\title{
Achieving Accuracy, Generalization-to-Contexts, and Complexity in Theories of Business-to-Business Decision Processes
}

\author{
Arch G. Woodside, Boston College \\ Roger Baxter, Auckland University of Technology
}

Submission: April 2011

Revision: November 2011

Revision: December 2011

Acceptance: May 2012

Industrial Marketing Management, forthcoming.

Send correspondence to Arch G. Woodside, Boston College, Carroll School of Management, Department of Marketing, 140 Commonwealth Avenue, Chestnut Hill, MA 02467; telephone/fax: +1-617 552-3069/6677 (arch.woodside@bc.edu); Roger Baxter, Faculty of Business, AUT University, Private Bag 92006, Auckland 1142, New Zealand, telephone: +64-9921-9999; fax +64-9-921-9629 (roger.baxter@aut.ac.nz). 


\section{Biographical Sketches of Authors}

Arch G. Woodside is Professor of Marketing, Carroll School of Management, Boston College, and a Fellow of the American Psychological Association, Association of Psychological Science, Society of Marketing Advances, the International Society for the Study of Tourism, and the Royal Society of Canada.

Roger Baxter is Senior Lecturer at the Auckland University of Technology, New Zealand, where he researches business relationships and teaches marketing. He has published in Industrial Marketing Management, the Journal of Business Research, and other journals. 


\section{Research Highlights}

- Our paper argues the case for increasing use of case study research in marketing

- The paper presents a selection of case study theories and methods

- The paper includes summaries of several examples of case study research 


\begin{abstract}
This article describes field research methods that provide advances in developing accurate theories of business-to-business (B2B) decision processes. The article supports and extends prior work by Woodside (2010) that bridging qualitative and quantitative research method is possible to achieve accuracy, complexity, and generality across cases in B2B decision processes. As an aid in doing so, the article argues for the study of a few ( $\mathrm{n}=5$ to 50 ) cases via case study research (CSR). The article defines CSR, and describes several CSR theories and methods that are useful for describing, explaining, and forecasting processes occurring in business-to-business (B2B) contexts. The discussion includes summaries of six B2B case studies spanning more than 60 years of research. This article advocates embracing the view that isomorphic theory of realities of B2B processes is possible via advances in CSR methods. The discussion advocates rejecting the dominant logic of attempting to describe and explain B2B processes by arms-length fixed-point surveys that usually involve responses from one executive per firm with no datamatching of firms in specific B2B relationships_-such surveys lack details and accuracy necessary for understanding, describing, and forecasting B2B processes.
\end{abstract}

\title{
Keywords
}

business-to-business relationship; case study research; direct research; participant observation; ethnographic decision tree model; fuzzy-set qualitative comparative analysis; degrees-offreedom analysis 


\section{Achieving Accuracy, Generalization-to-Contexts, and Complexity in Theories of Business-to-Business Decision Processes}

\section{Introduction}

This article points out how researchers of business-to-business (B2B) decisions can strengthen both the theoretical and the analytical basis of their research by broadening their range of research tools to include advances in case study research (CSR). As Hult (2011) points out, marketing researchers, including business-to-business (B2B) researchers, use an eclectic mix of theoretical bases for the understanding of phenomena. These theories include general-level theories of marketing, such as Hult's proposal of a marketing organization theory (MOT) and the Vargo \& Lusch service-dominant logic (2004) proposal; general theories from other disciplines such as the work of economist Penrose (1959); and mid-level bridging theories such as the contemporary marketing practices (Brodie, Saren, \& Pels, 2011).

Because B2B decision researchers are likely to continue to use a broad range of theoretical bases they will need a broader range of epistemologies and methodologies in future in order to investigate marketing phenomena in full depth using these theories (Nicholson, Lindgreen, \& Kitchen, 2009). The application of Giddens' (1979) structuration theory is an example. Researchers apply structuration concepts to marketing problems (Vallaster \& de Chernatony, 2006 ). Nicholson, Lindgreen and Kitchen (2009) propose structuration theory for wider application to relationship marketing to encompass multiple ontological paradigms and to cope with issues of time and space in longitudinal research. Structuration can also help account for both human agency and social structure, which would be beneficial at a fine-grained level of 
research (Hult, 2011) into the activities of the single human actor in a relationship (Baxter \& Olesen, 2008).

Different general level theories, whether scholars use them individually or in blended forms that incorporate more than one theory or paradigm, can potentially inform marketing research in different ways. However, ontological and epistemological tensions may occur in adopting theories, particularly when they embrace a wide range of paradigms. For example, studies that use structuration often apply it with an interpretivist approach such as the work of Orlikowski (1992) that recognizes multiple realities, whereas marketing tends to look for “one reality”, with realism as the predominant ontology (Healy \& Perry, 2000). Nicholson et al. (2009) argue that structuration can cope with multiple paradigms. However, debate rages about this in the literature (e.g. DeSanctis \& Poole, 1994; Sarason, Dean, \& Dillard, 2006). The use of structuration may involve a conflict of paradigms and thus involve epistemological and hence methodological conflict.

These issues of possible incommensurability of paradigms may or may not present problems, but B2B decision researchers do need to consider them. They need to do so particularly when they blend theories and paradigms because of the potential problems that blending brings (Okhuysen \& Bonardi, 2011). Researchers certainly need to understand how these epistemological issues affect the best choice of methodologies to deal with differing paradigms, which is relevant to the focus of this article. Although an orientation towards the more positivist, objectivist, and quantitative approaches may have served marketing researchers well in the past, researchers will continue to need a wider range of techniques. 
This article addresses some of the methodological issues and provides tools to deal with them. Even if researchers take the approach to research that there is "one imperfectly apprehensible reality” (Healy \& Perry, 2000), they need to recognize multiple perspectives within that approach. Such recognition requires at least a multiple-respondent approach if not a multipletechnique approach, with triangulation of data sources. Advances in CSR can help to apply these approaches (Woodside, 2010).

Before moving on to discussion of CSR foundations and specific techniques in more depth, the article now discusses what CSR is. In doing so, the article principally takes realism's one-reality multiple-perspective view. Although this discussion will not address the deeper ontological and epistemological issues that the use of new and blended theories and lenses potentially brings, it does provide a rationale for moving to a wider range of methodologies and analysis techniques and a basis for doing so.

\section{Nature of case study research}

CSR is an inquiry that focuses on describing, understanding, predicting, and/or controlling the individual (i.e., process, animal, person, household, organization, group, industry, culture, or nationality) (Woodside, 2010). This definition is intentionally broader than the definition that Yin (1994, p. 13) proposes, “A case study is an empirical inquiry that investigates a contemporary phenomenon within its real life context, especially when the boundaries between phenomenon and context are not clearly evident.” 
For a given study, focusing the research issues, theory, and/or empirical inquiry on the individual $(\mathrm{n}=1)$ is the central feature of CSR. As Skinner notes (1966, p. 21), “... instead of studying a thousand rats for one hour each, or a hundred rats for ten hours each, the investigator is likely to study one rat for a thousand hours.” This view is not intended to imply that CSR is limited to a sample of $n=1$. Reports of multiple case studies are available in organization science (e.g., Nutt, 1993, 1994) involving business-to-business contexts. In the marketing literature, Howard and Morgenroth (1968) illustrate transforming the research context in one supply chain from $n=1$ to n > 30 by examining alternative thought/action routes taken in separate, but seemingly similar, decisions that include five principal parties in the corporate context: a senior decision-maker, a regional manager, a local distributor, and two sets of competitors.

This article's objectives include achieving four outcomes. First, the article serves to inform the reader of core assumptions about B2B relationships that serve as rationales for conducting case study research in business-to-business (B2B) contexts. These rationales highlight the need for a range of methodological approaches that cope better with temporal and spatial transferability of results. Cross-sectional research findings, in particular, have the problem that they "offer weak transferability from one contextual setting to another” (Nicholson et al. 2009), whereas CSR, as explained below, has the potential to overcome that problem.

Second, the article provides brief summaries of exemplar methods in the literature of B2B decision-process studies. Third, the review of these studies provides principles for advancing a 
behavioral theory of the firm (Cyert and March, 1963). Fourth, the article provides examples of useful strategy implications that result from CSR reports.

\section{Core assumptions serving as rationales for CSR}

This section of the article outlines several assumptions that provide the rationale for the use of

CSR. A number precedes each of the core assumptions about B2B relationships that follow and that support the rationale for in-depth CSR. The first two assumptions are about the challenges that the environment poses in B2B research. Assumption (1) notes the concern that in B2B research, there are multiple perspectives of events. Assumption (2) notes different perspectives of participants and hence leads into the assumptions (3) to (6), which note human cognitive limitations that affect the ability to report events. For effective outcomes, researchers need to attend to "both blades of the scissors" (Simon, 1990; Todd \& Gigerenzer, 2003) where one blade is environmental issues and the other is cognitive limitations: studying "only one blade is not enough; it takes both for the scissors to cut.” Six assumptions follow as 3.1 to 3.6.

(1) B2B relationships include interactions among four-plus persons. For example, a buyer in a customer firm interacts with a vendor's sales representative and each reports their discussion with one or more persons in their respective firms. The metaphor of listening-to-one-hand-clapping has some relevancy in describing research that reports on interviews or survey answers of only one person who is a participant in a B2B context. Single-respondent research may present only one perspective of events among many and 
is therefore not sufficiently representative of the depth of meaning of events to be temporally and spatially transferable (Nicholson et al. 2009).

(2) Because participants differ in their perspectives and prior experiences to some important extent in B2B contexts, this contributes to the "multiple perspectives" of the events to which the research relates so that important differences occur in their descriptions of B2B processes and the causes and outcomes of these processes. To clarify and deepen knowledge of what is happening and how participants interpret thinking, actions, and outcomes, case study researchers prefer to observe meetings and interview two-plus persons that interact in B2B contexts. For example, case study researchers prefer to interview a B2B buyer and a B2B vendor separately as well as to observe their face-to-face meetings rather than rely on responses to a survey from one or the other participant.

Figure 1 illustrates these ideas as well as emphasizes the point that B2B contexts and processes involve several time periods (days, weeks, months, and years). Case study researchers have a strong preference to apply a triangulation of methods in collecting data - interviews of participants, analyses of documents, and direct observation of events such as meetings that are relevant for the same B2B process. They do this to address two issues noted below in more depth: the inability of participants to articulate the processes of intuitive decisions and actions and the varying perspectives of different observers. Triangulation is important in order to establish analytic generalizability and construct validity (Healy \& Perry, 2000). Case study researchers tend to interview the same 
persons on more than one occasion because they recognize that B2B processes are dynamic and occur over several time periods and hence that time issues are important to interaction in business relationships (Medlin, 2004).

If generalizability and/or theory testing is the aim of a study, case study researchers will collect data about, and analyze, multiple cases in order to better establish patterns across multiple contexts and “demonstrate convergence on one meaning” (Johnston, Leach, Liu, 1999). Researchers can test relevant types of hypotheses with multiple cases in three separate sets of theoretically relevant cases as suggested by Johnston et al. They can investigate the theorized hypotheses for replicability in a set of similar cases; investigate differences in selected different contexts; and investigate rival hypotheses.

Figure 1 here.

(3) Most thinking occurs unconsciously; humans have limited access to their unconscious thoughts (Wegner, 2002; Wilson, 2002). Dane \& Pratt (2007) discuss in depth the importance of nonconscious decision-making to management and point out that in many situations intuitive decision-making is superior to, or a very useful additional tool to, rational decision-making. The naturalistic decision making paradigm (Lipshitz, Klein, Orasanu, \& Salas, 2001), which relies on the concept of intuitive decision making, has been used to explain "how proficient decision makers are able to cope, and to perform relatively well in the face of complicated real-life challenges” (Vanharanta \& Easton, 2010). Vanharanta and Easton (2010) analyze meetings to show the intuitive nature of 
decisions based on Klein’s (1999) recognition-primed decision making (RPD) model and to show how RPD applies to managers forming business-to-business network pictures and using these network pictures to make decisions in their dealing with other network firms.

The extensive occurence of unconscious thinking means that respondents in business-tobusiness research, even though they may have a genuine wish to do so, simply can not fully verbalize situations, because they are not conscious of their own intuitive thought processes which lead to decisions. Hence the need for triangulation of data and techniques in order to uncover information that the managers cannot articulate. For example, in addition to interviews, the researcher might employ direct observation of firm processes, as was used by Vanharanta and Easton (2010) above and which is one of the CSR techniques described below.

(4) Humans edit their thoughts before responding to questions to defend their egos, to appear rational, and to hide information that they believe is best kept confidential to themselves and/or their firm—especially when talking with an interviewer for the first time or when completing a written survey. Managers also attempt, as do others, to achieve consonance of information through a drive to "cognitive consistency” (e.g. Simon \& Holyoak, 2002) whereby conflicts in information are resolved in the mind. This inevitably results in changes in perceptions of events and processes and consequent distortions, despite the best intentions of interview or survey respondents. As Simon, Snow, and Read (2004, p. 815) note, there are dynamic changes of cognitive elements, 
which go "from evidence to conclusions and from conclusions back to evidence" and that “consonance is restored by changing the elements that are in dissonant relations, adding consonant ones, or decreasing the importance of the dissonant elements”.

Consequently, case study researchers employ methods that include but frequently go beyond asking questions; these additional methods include document analysis (Pettigrew, 1973, 1975, 1995), direct observation (Mintzberg, 1979), and forced metaphor elicitation techniques (von Wallpach and Woodside, 2010), some of which are included in the CSR techniques described below.

(5) Thinking and making decisions in B2B relationships include creating "satisficing” (Simon, 1956) rules—decision makers do not attempt to identify and select optimal solutions even when they report doing so. Rather, they create and apply simple heuristics (rules that represent paths to accepting and rejecting options) (Gigerenzer \& Todd, 1999) and employ intuitive, perhaps more emotive, decision-making processes that do not attempt to use all the complex information that may be available in a rational process (Prietula \& Simon, 1989).

(6) Satisficing rules involve yes/no mental paths that include two or more attributes-not a compensatory evaluation involving summing-up -3 to +3 scores on 5 or so attributes. B2B decision-makers do not use compensatory heuristics even when they report doing so (Woodside and Wilson, 2000). Consequently, research on "key success factors” (Cooper, 1998) is insufficient for forecasting B2B behavior accurately; no one key success factor 
is sufficient or necessary in accepting or rejecting an option in a B2B context. Identifying key success paths (KSPs) and key failure paths (KFPs) is necessary for accurately forecasting B2B outcomes. This article includes examples of KSPs and KFPs.

Figure 2 serves to illustrate the core assumptions that this section presents. Note in Figure 2 that time and observability represent the $\mathrm{X}$ and $\mathrm{Y}$ axis, respectively. Unlike most respondent selfreport surveys, time and observability are principal explicit dimensions in most case studies. B2B CSR recognizes that B2B relationships-enactments include specific events (milestones) that connect with each other through time and that group meetings occur before, during, and after these enactments. As Figure 2 indicates, the same persons do not participate in all group meetings that represent B2B relationship enactments: this fact has implications for observability. Sentiments and beliefs in Figure 2 include implicit and explicit attitudes (positive and negative feelings) and cognitions (perceptions of associations among two or more attributes, behaviors, and outcomes).

Figure 2 here.

Groups as well as individuals form implicit and explicit sentiments and beliefs (SBs). SBs, behavior, and events relationships are dynamic; they mutually influence one another as participants struggle to make sense of what is happening, what should happen next, and what did happen just recently. Consequently, sensemaking about past, present, and future contexts and framing issues and opportunities is a core activity by participants in B2B contexts. Antecedents, 
processes, and outcomes of participants' sensemaking activities are frequently the major foci in B2B CSR.

A key conclusion from studying Figure 2 and the assumptions about B2B contexts is that most CSR requires substantial amounts of time to collect data in real-life settings. Participants'selfreports in one-shot surveys are a poor meal and miss documenting the dynamics and nitty-gritty details of B2B processes including implicit SBs. To clarify and deepen understanding, this article includes example CSR summaries that display these assumptions and how they operate in specific B2B contexts. The examples come from exemplar studies that employ CSR methods.

\section{Exemplar methods of decision processes in B2B contexts}

This section includes brief descriptions of five CSR methods that appear in the B2B literature. These methods include “direct research" and observing B2B processes, decision systems analysis (DSA), ethnographic decision tree modeling (EDTM), content analysis, degrees-of-freedom analysis (DOFA), and fuzzy-set qualitative comparative analysis (see FS/QCA.com). The discussion includes references for readers seeking additional sources for study; the study of the original studies is necessary for honing skills in CSR in B2B contexts. The discussion is not exhaustive; Woodside (2010) provides expositions of additional methods that are applicable in B2B CSR.

\subsection{Direct research and observing B2B processes}


Direct research includes going into B2B contexts and observing the activities and interviewing the participants in B2B processes. Direct research applies Mintzberg’s (1979, p. 582) definition of a strategy, "Defining a strategy as a pattern in a stream of decisions, our central theme has been the contrast between 'deliberate' strategies, that is, patterns intended before being realized, and 'emergent' strategies, patterns realized despite or in the absence of intentions.”

Direct research includes observing B2B contexts with the researcher in situ for a week, one month, several months, to a year or longer. Direct research includes a triangulation of data collected and the heart of the method is on-site interviews and face-to-face observations of B2B processes. The following description of one direct method study includes case studies of deliberate and emergent strategies “of periods of 30 or more years” (Mintzberg 1979, p. 582). This is a large project, at the present time involving a number of months of on-site research in each organization. We first spend a good deal of time reading whatever historical documents we can find, in order to develop thorough chronologies of decisions in various strategy areas. Then we switch to interviews to fill in the gaps in the decision chronologies and to probe into the reasons for breaks in the patterns (i.e., for strategic changes). (Mintzberg, 1979, p. 582)

Mintzberg (1979) describes the following seven "themes” in his CSR studies that relate to B2B contexts. (1) The research is purely descriptive (not prescriptive) as much as possible. (2) The research relies on simple — in a sense, inelegant—-methodologies (liking sitting in a manager's office and observing what she does). 
(3) The research has been as purely inductive as possible. Inductive research includes two essential steps according to Mintzberg (1979). The first is detective work, the tracking down of patterns, consistencies. “One searches through a phenomenon looking for order, following one lead to another. But the process itself is not neat (Mintzberg 1979, p. 584). The "creative leap" is the second step in induction.

The fact is that there would be no interesting hypothesis to test if no one ever generalized beyond his or her data. Every theory requires that creative leap, however small, that breaking away from the expected to describe something new. There is no one-to-one correspondence between data and theory. The data do not generate the theory — only researchers do that - any more than the theory can be proved true in terms of the data. All theories are false, because all abstract from data and simplify the world they purport to describe. Our choice, then, is not between true and false theories so much as between more and less useful theories. (Mintzberg, 1979, p. 584)

(4) The research is, nevertheless, systematic in nature: specific kinds of data are collected systematically. See Woodside’s (2010) discussion on “property space analysis” for systematic sampling to include cases of extreme behavior to achieve description and explanation of pure types—not just the most typical cases. 
(5) Research measurement is in real organizational terms. The researcher does not insist on forcing the B2B relationships into abstract categories. For an example of a definition and measurement in natural categories, see van Mannen’s (1978) study of “The Asshole”.

(6) The research, in its intensive nature, ensures that systematic data are supported by anecdotal data. Mintzberg offers the following insights about this sixth theme:

For while systematic data create the foundation for our theories, it is the anecdotal data that enable us to do the building. Theory building seems to require rich description, the richness that comes from anecdote. We uncover all kinds of relationships in our "hard" data, but it is only through the use of this "soft" data that we are able to "explain" them, and explanation is, of course, the purpose of research. (Mintzberg, 1979, p. 587)

Woodside (2010) presents anecdotal evidence of lying to a customer by a sales representative in a B2B context—not to suggest that lying always occur in such environments but that lying does occur sometimes in some specific circumstances (e.g., when a sales rep’s product repeatedly fails to perform).

(7) The research seeks to synthesize, to integrate diverse elements into configurations of ideal or pure types. B2B relationships are sometimes constant over weeks and months and sometimes dynamic for short spurts; they include all kinds of lags and discontinuities. Because relationships in real-life are asymmetrical rather than symmetrical, configural descriptions of 
B2B relationships are most useful and more accurate than structural equation models of these same relationships (see the FS/QCA discussion below in this article and Ragin, 2008; Woodside, 2010).

Eichenwald (2000) and Woodside and Samuel (1981) are two exemplar direct research studies that include participant observation (PO) in B2B contexts. In The Informant (Eichenwald 2000) an executive in an international manufacturing firm becomes an undercover researcher (with hidden cameras and listening devices) to collect data showing his colleagues planning and doing illegal price-fixing deals with executives in other firms.

In most studies PO data collection is obtrusive with the organizations' members knowing that a researcher is present for the purposes of observing, describing, and explaining what is occurring in the organization. Woodside and Samuel (1981) apply an ethnographic approach to develop flow diagrams of the information processes and decision making stages of corporate and plant executives in developing corporate purchasing agreements with suppliers.

The two-year, direct-observational case study by Cyert, Simon, and Trow (1956) is essential reading for honing skills in CSR methods in B2B contexts. Cyert et al. (1956) propose four "elements" (i.e., behavioral principles) from their study of a firm's decision process focusing on the "feasibility of using electronic data-processing equipment [a mainframe computer] in a medium size corporation that engages both in manufacturing and in selling through its own widely scattered outlets.” During the study, the focal firm's executives met with representatives of different vendors, held numerous committee meetings, hired two consulting firms to help the 
firm make sense of the situation and their need for a mainframe computer, and finally decided to back-away from the problem-and postponed making any decision other than continue-to-wait.

The four principles represent the cornerstones of “a behavioral theory of the firm” (Cyert and March, 1963); this theory focuses on describing and explaining vaguely defined, nonprogrammed problems and opportunities. We use brackets and CAPITAL LETTERS to summarize the four principles and to stress that the principles always occur-implicitly and/or explicitly_for non-programmed or semi-programmed decision-making in B2B contexts and elsewhere.

1. The alternatives are not usually "given" but must be sought, and hence it is necessary to include the search for alternatives as an important part of the process. [CREATE SEARCH ROUTINES FOR ALTERNATIVES.] 2. The information as to what consequences attach to which alternatives is seldom a "given," but, instead, the search for consequences is another important segment of the decision-making task. [CREATE SEARCH ROUTINES FOR CONSEQUENCES.]

3. The comparisons among alternatives are not usually made in terms of a simple, single criterion like profit. One reason is that there are often important consequences that are so intangible as to make an evaluation in terms of profit difficult or impossible. In place of searching for the "best" alternative, the decision-maker is usually concerned with finding a satisfactory alternative, one that will attain a specified goal and at the 
same time satisfy a number of auxiliary conditions. [CREATE SATISFICING HEURTISTICS.]

4. Often, in the real world, the problem itself is not a "given," but, instead, searching for significant problems to which organizational attention should be turned becomes an important organizational task [HONE SENSEMAKING SKILLS]. (Cyert et al. 1956, p. 237)

Cyert et al. (1956) is an insider's study in the B2B CSR literature-a well-spring reference for the reports that follow its publication (e.g., Mintzberg, Raisinghani, \& Theoret, 1976; Vyas and Woodside 19984; Na, Marshall, \& Woodside, 2009). Note that the fourth principle relates directly to Weick’s (1979) classic, Sensemaking in Organizations.

Sensemaking is interpreting a context and mentally reviewing appropriate responses (e.g., search, create heuristics, decide, act now, and wait) in the context. Though still missing explicitly in many B2B case study reports, sensemaking is a critically important CSR research topic in B2B and critically important for executives to do well. Creating and testing the effectiveness of executive training courses focusing explicitly on honing sensemaking skills in B2B contexts is a worthy focus for future research.

\subsection{Decision systems analysis (DSA)}

DSA includes building ethnographic and generalized visualizations (maps) and text explanations of the sensemaking steps, interactions of people, decision processes, and 
outcomes in real-life B2B contexts. DSA is one operational method for Mintzberg's seventh theme: building theoretical configurations of what happens in organizations.

Hulbert, Farley, and Howard (1972) were the first to describe the theory and empirical steps of doing DSA in B2B contexts. Examples with elaborations of the method in B2B contexts include the following studies: Capon and Hulbert (1975), Howard, Hulbert, and Farley (1975), Hulbert (1981, 2003), Johnston and Bonoma (1981), Na, Marshall, and Woodside (2009), and Vyas and Woodside (1984).

Figure 3 is an example map from a DSA of the thoughts, decisions, and outcomes involving manufacturers, distributors, and customers in the United States office furniture industry. Woodside (2003) provides additional maps and explanations of the configural processes in this B2B context.

Figure 3 here.

View Figure 3 as a specific example of the visual generalization of B2B processes that Figure 2 presents. Note that several individuals and firms appear in Figure 3 during what appears at first blush to be a "muddling through process” (Lindbloom, 1959). DSA helps to clarify and deepen understanding of real-life B2B processes-removes the mud in the context and cataracts from the eyes of the viewer. 
Table 1 summarizes the steps and frequencies of paths taken by the focal office furniture distributor in Woodside’s (2003) study. The ability to model the occurrence of such paths shows how DSA can be a step toward building more advanced theory-building and testing methods, that is, ethnographic decision-tree modeling and qualitative comparative analysis (QCA) models (see Ragin, 2008).

Table 1 here.

\subsection{Ethnographic decision tree modeling (EDTM)}

EDTM includes the following characteristics: data on search for information, sensemaking, creating heuristics, and choice in non-programmed or semi-programmed decisions are collected in real-life field settings. The researcher asks or observes an individual or group of decision makers thinking aloud or role-playing as they perform the process once-per-several (usually $\mathrm{n}<$ 30) individuals or groups or several-times (usually $n>30$ ) for the same in individual or group. EDTM includes creating binary flow models leading to specific decision outcomes (e.g., accept versus reject a new product or increase, decrease, or keep price the same) and tests the efficacy of the models to predict outcomes in a holdout sample of cases.

Gladwin (1989) and colleagues provide several insightful ethnographic studies set in B2B contexts. Her studies include creating composite EDTM representations of real-life B2B decisions. For example, "In Eastern Zambia, this methodology was used to study the decisions of small-scale farmers [121 case studies], including female headed households (FHHs), to adopt agroforestry innovations in the form of improved fallows, researched by ICRAF, the International Centre for Research on Agroforestry, and recently promoted and extended by 
World Vision International, and monitored by the University of Florida Soils CRSP (collaborative research support program)” (Gladwin, Peterson, \& Mwale 2002). Gladwin’s studies focus on cognitive science reporting on the thinking and deciding processes that are representative of cases of individuals and firms engaging in sensemaking and deciding about the same issue (e.g., adopting or rejecting an agroforestry innovation.

EDTM captures and shows an important principle in behavioral (real-life) decision making; EDTMs indicate key success paths rather than "key success factors.” Identifying key success factors can be misleading since no simple antecedent condition is sufficient or necessary to cause a given outcome. Describing and explaining "key success paths" and "key failure paths" are usually necessary to have an accurate understanding of B2B decision processes.

Howard and Morgenroth (1968) and Morgenroth (1964) provide EDTMs of decisions makers in the same petroleum company making pricing decisions. Their analysis includes the use of a holdout sample to test the predictive validity of the final version of the study's EDTM. The two papers are essential readings in CSR in B2B contexts.

Woodside and Wilson (2000) provide EDTMs of individual and group decisions of both a manufacturer and customer firms for industrial solvents. The study describes a substantial variance in price-settings for different decision paths by the manufacturer. The study confirms the view that multiple, complex, antecedent conditions (causal recipes or configurations) rather than simple antecedent conditions are sufficient (but each recipe is not necessary) for causing a high price with other causal paths leading to a low prices. 


\subsection{Content analysis}

Examining written communications such as minutes of meetings is one example of content analysis. Asking participants to read and help revise drafts of EDTM's and a researcher's written case report on the participants' decision processes is another example of content analysis.

Pettigrew's $(1975,1995)$ longitudinal analysis of written communications among senior, middle, and first-line managers is an example of content analysis of multiple communications written and read by participants (and Pettigrew as a researcher) in a B2B context. Pettigrew's findings support his conclusion that the middle-manager revised and controlled both the content and flow of communications in ways unrecognized by senior and first-line managers. Pettigrew concludes that the middle-manager's gatekeeper's actions enabled him to direct both the senior managers and first-line managers to accept his views about selecting and rejecting competing vendors. Thus, the title of Pettigrew's seminal article, "the industrial purchasing decision as a political process.”

Morgenroth's (1964) remarkable article includes several revisions of EDTMs—each revision is based on content analysis by participants in the decision processes to earlier versions of Morgenroth's maps. Thus, the researcher asked the participants to further reflect and help revise the researcher's interpretations and mapping of the decision process. Morgenroth kept returning to the participants for follow-up interviews and new versions of his maps until both he and the participants were satisfied with the accuracy and completeness of the final EDTM. 
Emic interpretations are the interpretative (sensemaking) views of a participant as to what has happened, what is happening now, and what will happen next. Etic interpretations are the interpretative (sensemaking) views of the researcher about what has happened, what is happening now, and what will happen. Morgenroth (1964) reports multiple-rounds through several time periods $\left(\mathrm{t}_{\mathrm{i}}\right)$ of emic and etic interpretations of documents (maps) of how participants in a firm make pricing decision, for example: emic $\rightarrow \mathrm{etic}_{2} \rightarrow \mathrm{emic}_{2} \rightarrow \mathrm{etic}_{3} \rightarrow \mathrm{emic}_{3} \rightarrow \mathrm{etic}_{3}$. Such a reflective content analysis represents a hermeneutic spiral to achieve highly accurate and complete interpretations—-both explicit and implicit interpretations. Hermeneutics refers to the study of interpreting texts including the study of how to improve the accuracy in interpreting.

Woodside, Pattinson, and Miller (2005) and Pattinson and Woodside (2009) propose a five-level hermeneutic analysis framework. Figure 4 summarizes the initial levels of understanding and research on B2B decision making - up to four levels of hermeneutic analysis. Level I depicts the specific interpretations of the B2B executives descriptions and explanations of what happened and why it happened for a focal decision making issue. In Figure 4 Level I analysis shows that mental models are crafted and revised during the decision and action under study—at time t.

The executive's later $(t+1)$ interpretation and reporting of what happened represents both a summary and an elaboration of the mental models originating during the decisions-actions. These self reporting interpretations are subject to self-editing, memory failure, and personal prejudices and biases (Wegner 2002). 
Figure 4 here.

The hermeneutic analysis framework breaks through the current (early $21^{\text {st }}$ Century) dominant logic in B2B research which usually stops at collecting Level I data. Arrow a in Figure 4 represents a summary of what the participants in the enterprise report about the decision process under study.

Level II recognizes that a participant's $\mathrm{t+1}$ interpretation of what happened at a previous time, and why it happened, is one view of specific situations, decisions, and outcomes. This participant's emic view does not reflect a complete or a completely accurate account of reality. The researcher provides further commentary and often judgments (arrow c) on the participant's sensemaking account. The researcher collects (arrow b) additional interviews with other participants and/or analyzes documents to confirm, deny, and elaborate on the participant's report. Most B2B case study research extends to Level II research (see Woodside 2003).

Level III analysis supports Langley et al.’s (1995, p. 277) “suggestion 5 (to), reanalyze previously analyzed decision processes not just new ones.” Level III provides two etic interpretations with an additional time period and usually independent researchers. Etic 2 interpretations include commentaries of etic 1 , emic 1 , and mental models and decision process at the time of the original situation—relationships $\mathbf{d}, \mathbf{f}$, and $\mathbf{e}$, respectively. Level III analysis here includes chronologically mapping events of the decision process and outcomes reported by the etic 1 researcher. In this framework, the etic 2 researcher applies decision systems analysis (DSA, see Howard et al. 1975) based on the text of the original case study done by the etic 1 researcher. Woodside et al. (2005) provide a detailed package of extended DSA using a DSA 
model, an events chronology map and sets of cognitive maps (for more detail see Woodside et al. 2005). Level III analysis may contain content analysis supported by software tools including TACT (TACT, 1997) and NVivo (QSR International, 2002).

Level IV analysis incorporates an additional round of interviewing of one or more of participants involved in the case study reported by the etic 1 researcher. Participants are asked questions initially related to the etic report mainly addressing accuracy, completeness, and key elements within the report. They are then asked questions that address accuracy, completeness and suggested updates to the etic 2 material presented to them, which in turn constitute updates to the etic 1 case study account.

Level V analysis includes reinterpretation of all prior emic and etic sets of interpretations. Level $\mathrm{V}$ analysis is classifiable as an advanced hermeneutic interpretation because the analysis includes three rounds of separate etic interpretations that help builds toward sensemaking views of the whole case study.

\subsection{Degrees-of-freedom analysis (DFA)}

DFA is the attempt to deepen understanding and accuracy in a case study by identifying how well the features in the case match competing explanations (normative theories and theories-inuse by participants) about what has happened and the explanations of the causes and outcomes relevant to what has happened. 
Campbell (1975) introduces and advocates DFA in case study research. He maintains that this pattern-matching activity is analogous to having degrees-of-freedom in a statistical test:

In a case study done by an alert social scientist who has thorough local acquaintance, the theory he uses to explain the focal difference also generates predictions or expectations on dozens of other aspects of the culture, and he does not retain the theory unless most of these are also confirmed. In some sense, he has tested the theory with degrees of freedom [emphasis added] coming from the multiple implications of one theory (Campbell, 1975, pp. 181-182).

Such analysis considers case data quantitatively because the researcher notes the degree of match to the theory in terms of "hits and misses." How many hits are necessary to "confirm" the theory? Simple statistical tests are useful for noting whether or not the number of hits or misses is greater than that expected by chance. Or, the researcher may conduct DFA purely to note the absolute number of confirmed predictions for the sake of basic knowledge development (without worrying about whether results are "statistically significant"). This aspect of degrees-of-freedom analysis is consistent with Denzin and Lincoln’s (1994) observation, as follows.

Nor does qualitative research have a distinct set of methods that are entirely its own. Qualitative researchers use semiotics, narrative, content, discourse, archival, and phonemic analysis, even statistics [emphasis added]. (Denzin and Lincoln’s (1994) 
The contribution of DOF is in demonstrating how researchers can link "traditional" (i.e., logical positivistic) hypothesis testing procedures to examine theoretical propositions in case study research. This approach is one way of achieving a "critical test” (Carlsmith, Ellsworth, and Aronson, 1976) that is, testing the relative empirical strengths and contextual relevancy of competing theories. See Woodside (2010) for details and statistical testing of DFA in B2B contexts.

\subsection{Fuzzy-set qualitative comparative analysis (fs/QCA)}

The FS/QCA method bridges quantitative and qualitative approaches because the methods in this tool kit are simultaneously qualitative and quantitative (Ragin, 2008, p. 82). FS/QCA focuses on analyzing alternative combinations of antecedent conditions that represent causal complexity rather than the analysis of net effects; FS/QCA identifies causal recipes (specific combinations of causally relevant ingredients relating to an outcome) and thereby unravels causal complexity.

FS/QCA builds on set theory and fuzzy sets (Zadeh, 1965) analysis using Boolean algebra rather than linear algebra. Examining all logically possible combinations of causal conditions makes it possible to construct experiment design-like contrasts (where only one causal condition at a time is allowed to vary) and thus offers a thorough analysis of the effects of relevant causal

conditions. In effect, the impact of each cause is examined in all logically possible contexts (the 2k configurations of conditions, k=number of causal conditions) (Ragin, 2008: 125).

The following discussion is a brief introductory example of FS/QCA. A fuzzy set scale allows for fine gradations of the degree of membership in a causal conditional recipe. A fuzzy set is viewable as a purposively calibrated scale transformation of a continuous variable. Such 
calibration is possible only through the use of theoretical and substantive knowledge that is essential in the specification of the three qualitative breakpoints (full membership=1.0; full nonmembership=0.0; and maximum ambiguity—the crossover point=0.5) (Ragin, 2008: 30).

Figure 5 illustrates the creation of three fuzzy set purposively calibrated scales from case data in a business-to-business process study of marketing and purchasing industrial chemicals (Woodside and Wilson, 2000). Less than 1\% of all customers for the large manufacturer of industrial chemicals were fully in the membership of customers with large purchase requirements. Customers with purchase requirements for the category of chemicals in this study are classifiable more out than in the large customer requirements membership. The manufacturer classifies customers willing to single source $90 \%$ plus of their purchase requirements for the category as fully in the membership of customer willing to single source.

Figure 5 here.

Customers buying 50 percent of their requirements from this manufacturer are classifiable as more out than in membership of willing to single source. Customers aggressively demanding price reductions plus additional benefits (e.g., the manufacturer building storage facilities for the category on the customers' site at no charge) are classifiable as fully in the membership of customer aggressive with respect to price setting. Customers demanding "cost avoidance" objectives (i.e., price increases less than published inflation rates for the category) are classifiable at the crossover point. Customers expressing willingness to pay "market prices" for 
the category are classifiable as more out than in membership for customer aggressiveness with respect to price.

Three common operations on fuzzy sets are set negation, set intersection (“logical and”), and set union ("logical or”). "Logical and” compound sets form by the combination of two or more sets, an operation commonly known as set intersection. With fuzzy sets, taking the minimal membership score of each case in the sets that are combined, accomplished a "logical and”, that is, a set intersection.

Table 2 includes the fuzzy set scores and the set intersection of their three-way combination (causal recipe) for eleven customers in the study of marketing and buying of industrial chemicals. The midlevel dots are used to indicate set intersection (combination of aspects) for the three causal conditions $(\mathrm{A} \cdot \mathrm{B} \cdot \mathrm{C})$. Note the intersection scores are equal to the lowest score from the three prior columns in Table 2. The intersection value indicates the degree each case is more in or out of the intersection membership.

Negation: a fuzzy set can be negated to indicate the degree that the case is not a member of the set. To calculate the membership of a case in the negation of fuzzy set A, simply subtract its membership in set A from 1.0 as follows: (Membership in set $\sim A)=1.0-($ Membership in set A) or $\sim \mathrm{A}=1.0-\mathrm{A}$, where “ $\sim$ " indicates negation. Thus, for customer case number 1 , its membership in (Not a member of the large customer group) has a negative score of 0.1 . Note that negation membership, “not a large customer,” is asymmetric to membership in the target concept of small customer membership, that is, a customer can be more in the out than in the large 
customer membership (Not a member of large customers) and still not be full member of the small customer membership. This point holds for the other two causal conditions (B and C) in Table 2. Dual coding of key causal conditions has important theoretical benefits.

Table 2 here.

Logical or: two or more sets also can be joined through the logical or: the union of sets. The logical or directs the researcher's attention to the maximum of each case's memberships in the component sets. A case's membership in the set formed from the union of two or more fuzzy sets is the maximum value of its memberships in the component sets. The addition sign is used to indicate logical or, for example the logical or membership for case number 1 for the combination of the three causal conditions in Table 2 equals: $\mathrm{A}+\mathrm{B}+\mathrm{C}=0.9$.

With fuzzy sets, membership scores in one set (a causal condition or a combination of causal conditions) that are less than or equal to their corresponding membership scores in another set (e.g., the outcome) indicates a subset relationship. Observe in Table 2 that the causal recipe membership score for $\mathrm{A} \cdot \mathrm{B} \cdot \mathrm{C}$ are consistently less than or equal to their corresponding membership scores in customer share of business awarded to firm X (the chemical manufacturer marketing the category) in the study—with the exception of customer case number 11.

Figure 6 shows the plot of the causal recipe of the intersection representing the conjunction of the causal conditions $(\mathrm{A} \cdot \mathrm{B} \cdot \mathrm{C})$ and the outcome membership of customer share of business awarded to firm X. The pattern of results is consistent with an argument of sufficient causation- 
an upper-left triangular plot, with the degree of membership in the causal combination of the horizontal axis and the degree of membership in the outcome on the vertical axis, signals the fuzzy set relation.

Figure 6 here.

The plot in Figure 6 shows sufficiency but not necessity for the conjunction of $A \cdot B \cdot C$ on the outcome membership. Other paths to high membership scores on the outcome condition exist but this observation does not take away from the finding of sufficiency in high membership scores in the causal recipe resulting in high membership scores in the outcome condition-the argument of sufficiency but not necessity permits multiple paths to high scores for the outcome condition.

\subsubsection{Measures of associations}

Consistency, like significance, signals whether or not an empirical connection merits the close attention of the investigator. If findings from the membership analysis are inconsistent with the hypothesized relation, then the hypothesis or conjecture is not supported (Ragin, 2008: 45). Coverage, like strength, indicates the empirical relevance or importance of a set-theoretic connection. Coverage estimates assess the proportion of cases following a path to high outcome scores; coverage is a straightforward indicator of the empirical importance of a causal combination (Ragin, 2008, p. 55). 
The formulas and specific estimates for consistency and coverage for the causal combination (conjunction A-B.C) appear at the bottom of Figure 4. The evaluation of the set relationships between the causal recipe and the outcome condition indicates high consistency and moderate amount of coverage.

The uniqueness of case number 11 in the findings in Table 1 and Figure 4 merits further attention and its discussion permits extending Gibbert’s (2006) observations about "generalizing about uniqueness.” Further discussion about customer 11 with the manufacturer marketing the category resulted in confirmation of this customer's unique relationship with this marketer. The manufacturer sales manager reported monthly complaints by this customer and continuing attempts to renegotiate prices during the annual contract. While this sales manager did not use the expression, customer 11 reflects the industrial customer equivalent to van Maanen (1978) “The Asshole," in his study of a distinct but familiar type of person to the police. Thus, unique findings indicate a paradox worthy of further investigation. "Generalizability demands the research findings are not idiosyncratic to the firm or the sample of firms studied” (Gibbert, 2006, p. 124). Thus, the researcher should look for the presence of further assholes or other seemingly unique cases before concluding that adding condition D is relevant for model building and testing.

Creating a fourth causal condition, $\sim \mathrm{D}=$ "not an Asshole" would place all customers in Table 1 above the crossover point (0.5) except for customer 11. Customer 11's low score on this causal condition $(\sim \mathrm{D}=0.00$ for customer 11$)$ would shift his $\mathrm{A} \cdot \mathrm{B} \cdot \mathrm{C} \cdot \sim \mathrm{D}$ conjunction score to the left and result in high consistency for this more complex causal recipe. 
Note that Table 1 and Figure 8 examine only one causal condition's relation to the outcome condition. Additional causal conditions warrant examination and these include A, B, C, A.B, $\mathrm{A} \cdot \mathrm{C}, \mathrm{B} \cdot \mathrm{C}, \sim \mathrm{A} \cdot \mathrm{B} \cdot \sim \mathrm{C}$, as well as $\sim \mathrm{A} \cdot \mathrm{B} \cdot \mathrm{C}$, and others. Ragin, Drass, and Davey (2007) provide a software program (www.fsqca.com) to ease the calculations involved in creating complex conditions and estimating their consistency and coverage.

\section{Useful strategy and theory implications resulting from case reports}

This section offers a few insights into how CSR reports aid the effective application of a wide range of theories and hence of epistemologies and methodologies. Hence, they may influence planning, implementing, and evaluating strategies in B2B contexts, because B2B CSR often contain nitty-gritty identifiable details of processes relating to thinking, deciding, and doing among interacting participants that lead to successful versus unsuccessful outcomes. Several CSR methods inherently recognize that the B2B researcher needs to explicitly include time in collecting data and modeling B2B relationships (Woodside 2006), that is generally more achievable with CSR than with, for example, cross-sectional surveys.

What does a manufacturer with an average reputation need to do to gain new product acceptance by executives in a supermarket buying committee? Figure 5 indicates two strategy paths lead to acceptance for such a manufacturer. The point here is that creating accurate EDTMs is helpful for indentifying specific actions necessary to implement in specific contexts. 
Why are price decreases more complex than price increases? Howard and Morgenroth (1968) provide the answer. CSR includes methods that provide valuable instruction to executives not only to be mindful in making decisions but how to go about becoming mindful.

CSR methods include the use of empirical positivistic (statistical) tests. For example, using DOFA for testing the efficacies of competing theories compares hits and misses of theories to features present in a case. However, case study researchers have a natural bias against using seven-point scales. Mintzberg (1979) provides a telling explanation for this bias.

"Hmmmm ... what have we here? The amount of control is 4.2, the complexity of environment, 3.6.” What does it mean to measure the "amount of control" in an organization, or the "complexity" of its environment? Some of these concepts may be useful in describing organizations in theory, but that does not mean we can plug them into our research holus-bolus as measures. As soon as the researcher insists on forcing the organization into abstract categories — into his terms instead of its own — he is reduced to using perceptual measures, which often distort the reality. The researcher intent on generating a direct measure of amount of control or of complexity of environment can only ask people what they believe, on seven-point scales or the like. He gets answers, all right, ready for the computer; what he does not get is any idea of what he has measured. (What does "amount of control" [or "trust”] mean anyway?) The result is sterile description, of organizations as categories of abstract variables instead of flesh-and-blood processes. And theory building becomes impossible. (Mintzberg, 1979, p. 586) 
By direct research, content analysis, FS/QCA, and applying additional CSR methods, the researcher stays close to the data and can use alternative metrics to rigorously test the accuracy of complex antecedent conditions and paths leading to success and failure—and do so in terms that relate to real-life contexts. Such testing achieves the objective of generalizing the findings to multiple decisions made in a context (e.g., EDTM by Howard and Morgenroth, 1968, and Gladwin et al., 2002) and across multiple cases (e.g., FS/QCA by Ragin, 2008 and Woodside, 2010).

\section{Summary}

CSR is an inquiry focusing on describing, understanding, predicting, and/or controlling the individual (i.e., process, animal, person, household, organization, group, industry, culture, or nationality). Any combination of the following purposes may serve as the major objective of CSR: description, understanding, prediction, or control. However, that deep understanding of the actors, interactions, sentiments, and behaviors occurring for a specific process through time is the principal objective by the case study researcher. The researcher should consider using explicit auto-driving tools to aid in bringing-up unconscious mental processes among informants (e.g., the hermeneutic spiral that Woodside et al., 2005, and Pattinson and Woodside, 2008, describe) to overcome the cognitive limitations of reports noted in core assumptions (3) to (6) above.

A mental model of a process provided by a participant interviewed in a case study is an emic representation of reality. The interpretation of the same process provided by the case study researcher is an etic representation of reality. Etic representation in CSR often includes 
description and explanation of emic meaning as well as building composite accounts of the process based on data from triangulation. Triangulation includes: (1) direct observation by the researcher within the environments of the case, (2) probing by asking case participants for explanations and interpretations of operational data, and (3) analyses of written documents and natural sites occurring in case environments.

Core criticisms made by case study researchers of large sample surveys consisting of interviews of one person, informal group, or organization include: (1) the failure to confirm reported conversations, behaviors, and events, (2) the failure to collect the necessary detail for gaining deep understanding of the mechanics and reasons embedded in the processes examined, and the (3) use of response scales too far removed from reality of what they intend to measure. In contrast, when researchers use multiple data sources and techniques, they are more likely to deal effectively with both the environmental issues and the cognitive limitations noted in the six core assumptions early in this article than if they use single-instrument single-informant crosssectional studies. They are also able to deal better with a variety of theories and paradigms, whether used individually or in blended form. This is important for marketing researchers as they use a wide range of theories.

Core variables in CSR include individual and group behaviors through time resulting in a sequence of paths of events (decisions, performance outcomes, and revelatory incidents). Beliefs and sentiments held by individuals and groups are additional core variables that CSR reports. No one CSR method is appropriate for all studies: a range of tools is appropriate. 
Explanations with examples of additional CSR methods are available elsewhere (e.g., Woodside 2010). The coverage here serves only to introduce some methods useful for advancing theory of B2B decision processes that provides accurate descriptions and explanations and generalizes beyond an individual case study. 


\section{References}

Baxter, R., \& Olesen, K. (2008). Using Structuration Theory to Analyse Relationship Value CreationUppsala University. Symposium conducted at the meeting of the 24th IMP Conference, Uppsala, Sweden. Retrieved from http://www.impgroup.org/paper_view.php?viewPaper=6864 http://www.impgroup.org/uploads/papers/6864.pdf

Brodie, R. J., Saren, M., \& Pels, J. (2011). Theorizing about the service dominant logic: The bridging role of middle range theory. Marketing Theory, 11(1), 75-91.

Calder, B. J. (1977), Structural Role Analysis of Organizational Buying: A Preliminary Investigation, in Consumer and Industrial Buying Behavior, ed. by A.G. Woodside, J. N. Sheth, and P. D. Bennett, Elsevier, New York.

Capon, N., \& Hulbert, J. (1975), Decision systems analysis in industrial marketing, Industrial Marketing Management, 4, 143-160.

Carlsmith, J. Ellsworth, M. C., and Aronson, E. (1976), Methods of Research in Social Psychology, Reading, MA: Addison Wesley Publishing Company.

Cooper, R.G. (1998), Benchmarking new product performance: results of the best practices study, European Management Journal, 16, 1-17

Cyert, R. M., and J. G. March (1963), A Behavioral Theory of the Firm (Englewood Cliffs, New Jersey: Prentice-Hall.

Cyert, R. M., Simon, H. A., \& Trow, D. B. (1956), Observation of a business decision, Journal of Business, 29(October), 237-238.

Dane, E., \& Pratt, M. G. (2007). Exploring Intuition and its Role in Managerial Decision Making. Academy of Management Review, 32(1), 33-54. 
DeSanctis, G., \& Poole, M. S. (1994). Capturing the Complexity in Advanced Technology Use: Adaptive Structuration Theory. Organization Science, 5(2), 121-147.

Denzin, N. K., \& Lincoln, Y. S. (1994), Introduction: Entering the field of qualitative research, In: N. K. Denzin \& Y. S. Lincoln (eds.), Handbook of qualitative research. Thousand Oaks, CA: Sage.

Eichenwald, K. (2000), The Informant, New York: Broadway Books, Inc.

Gibbert, M. (2006), Generalizing about uniqueness, Journal of Management Inquiry, 15(2), 145151.

Giddens, A. (1979). Central Problems in Social Theory: Action, Structure and Contradiction in Social Analysis. Berkeley, CA: University of California Press.

Gladwin, C.H. (1989), Ethnographic decision tree modeling, Newbury Park: Sage.

Gladwin, C.H., Peterson, J.S., and Mwale, A.C. (2002), The Quality of Science in Participatory Research: A Case Study from Eastern Zambia, World Development 30 (4), 523-543.

Gigerenzer, G., \& Todd, P. M. (1999). Simple Heuristics That Make Us Smart. New York: Oxford University Press.

Healy, M., \& Perry, C. (2000). Comprehensive criteria to judge validity and reliability of qualitative research within the realism paradigm. Qualitative Market Research: An International Journal, 3(3), 118-126.

Howard, J. A., \& Morgenroth, W. M. (1968), “Information processing model of executive decisions,” Management Science, 14(3), 416-428

Howard, J. A., J. M. Hulbert, and J. U. Farley (1975), “Organizational Analysis and Information System Design: A Decision Process Perspective,” Journal of Business Research, 3 (April), 133-148. 
Howard, J. A., and W. M. Morgenroth (1968), Information Processing Model of Executive Decision, Management Science, 14 (3), 416-428.

Hulbert, J. (2003), Organizational analysis and information system design: A road revisited, Journal of Business and Industrial Marketing, 18(6/7), 509-513.

Hulbert, J. M. (1981), Descriptive models of marketing decisions, in Marketing Decisions Models, Randall L. Schultz and Andris A. Zoltners, eds. New York: North-Holland, 1953.

Hulbert, J.M., J. U. Farley, and J. A. Howard (1972), Information processing and decision making in marketing organizations, Journal of Marketing Research, 9 (February), 75-77.

Hult, G. (2011). Toward a theory of the boundary-spanning marketing organization and insights from 31 organization theories. Journal of the Academy of Marketing Science, 39(4), 509536.

Johnston, W. J. and T. V. Bonoma (1981), The Buying Center: Structure and Interaction Patterns, Journal of Marketing, 45 (Summer), 143-156.

Johnston, W. J., M. P. Leach, and A. H. Liu (1999), Theory testing using case studies in business-to-business research, Industrial Marketing Management, 28, 201-213.

Klein, G. (1999). Sources of Power: How People Make Decisions. Cambridge, Mass.: MIT Press.

Langley, A., Mintzberg, H. Pitcher, P. Posada, E., and Saint-Macary, J. (1995), Opening up decision making: The view from the black stool, Organization. Science, 6 (3), 260-279. Lindblom, C. E. (1959), The Science of Muddling Through, Public Administration Review, 19 (February), 79-99. 
Lipshitz, R., Klein, G., Orasanu, J., \& Salas, E. (2001). Focus Article: Taking Stock of Naturalistic Decision Making. Journal of Behavioral Decision Making, 14(5), 331-352.

Medlin, C. J. (2004). Interaction in business relationships: A time perspective. Industrial Marketing Management, 33(3), 185-193.

Montgomery, D. F. (1975). New product distribution: An analysis of supermarket buyer decisions. Journal of Marketing Research, 12(3), 255-264.

Mintzberg, H. (1979), An Emerging Strategy of ‘Direct’ Research, Administrative Science Quarterly, 24 (December), 582-589.

Mintzberg, H., Raisinghani, D., \& Theoret, A. (1976), The structure of unstructured decision processes, Administrative Science Quarterly, 21 (2), 246-275.

Morgenroth, W. M. (1964), “Method for understanding price determinants,” Journal of Marketing Research, 1(3), 17-26.

Na, W. B., Marshall, R., \& Woodside, A. G. (2009), Decision system analysis of advertising agency decisions, Qualitative Market Research: An International Journal, 12(2), 153170.

Nicholson, J., Lindgreen, A., \& Kitchen, P. (2009). Spatial and temporal specificity and transferability: Structuration as the relationship marketing meta-theory. Qualitative Market Research: An International Journal, 12(2), 187-207.

Nutt, P. C. (1993), The formulation processes and tactics used in organizational decision making, Organization Science, 4 (2), 226-251.

Nutt, P. C. (1984), Types of organizational decision processes, Administrative Science Quarterly, 29 (3), 414-450. 
Okhuysen, G., \& Bonardi, J.-P. (2011). Editors' comments: The challenges of building theory by combining lenses. Academy of Management Review, 36(1), 6-11.

Orlikowski, W. J. (1992). The duality of technology: rethinking the concept of technology in organizations. Organization Science, 3(3), 398-427.

Pattinson, H.M. and Woodside, A.G., (2008), Capturing and (re)interpreting complexity in multifirm disruptive product innovations, Journal of Business \& Industrial Marketing, 24 (1), $61-76$.

Penrose, E. T. (1959). The Theory of the Growth of the Firm. Oxford: Basil Blackwell.

Pettigrew, A. M. (1973), The Politics of Organizational Decision Making. London: Tavistock.

Pettigrew, A. M. (1975), The industrial purchasing decision as a political process, European Journal of Marketing, 9 (March), 4-19.

Pettigrew, A. M. (1995), Longitudinal field research on change: theory and practice, in Longitudinal Field Research Methods, ed. by George P. Huber and Andrew H. Van De Ven, Thousand Oaks, CA: Sage, 91-125.

Prietula, M. J., \& Simon, H. A. (1989). The experts in your midst. Harvard Business Review, 67(1), 120-124.

Ragin, C. C. (2008), Redesigning social inquiry: Fuzzy sets and beyond. Chicago: Chicago University Press.

Ragin, C., Drass, K., \& Davey, S. (2007). Fuzzy-Set/Qualitative Comparative Analysis 2.0 (available at http://www.u.arizona.edu/Bcragin/fsQCA/software.shtml).

Sarason, Y., Dean, T., \& Dillard, J. F. (2006). Entrepreneurship as the nexus of individual and opportunity: A structuration view. Journal of Business Venturing, 21(3), 286-305. 
Skinner, B. F. (1966), Operant behavior, in W. K. Honig (ed.), Operant Behavior: Areas for Research and Application, New York: Appleton-Century-Crofts, 12-32.

Simon, D., \& Holyoak, K. J. (2002). Structural dynamics of cognition: from consistency theories to constraint satisfaction. Personality \& Social Psychology Review (Lawrence Erlbaum Associates), 6(4), 283-294.

Simon, D., Snow, C. J., \& Read, S. J. (2004). The redux of cognitive consistency theories: evidence judgments by constraint satisfaction. Journal of Personality \& Social Psychology, 86(6), 814-837.

Simon, H. A. (1956), "Rational choice and the structure of the environment,” Psychological Review, 63, 129-138.

Simon, H. A. (1990). Invariants of human behavior. Annual Review of Psychology, 41(1), 1. QSR International (2002), NVivo, V 1.3, WINDOWS XP, (www.qsr.com.au).

Todd, P. M., \& Gigerenzer, G. (2003). Bounding rationality to the world. Journal of Economic Psychology, 24(2), 143-165.

TACT (1997), http://www.indiana.edu/ letrs/help-services/QuickGuides/about-tact.html. van Maanen, J (1978). The asshole, in: P. K. Manning \& J. Van Maanen (Eds.), Policing: A view from the street. Santa Monica, CA: Goodyear Publishing (available at http://petermoskos.com/readings/Van_Maanen_1978.pdf).

Vyas, N., and Woodside, Arch G. (1984), An inductive model of industrial supplier choice processes, Journal of Marketing, 47, 30-44.

Vallaster, C., \& de Chernatony, L. (2006 ). Internal brand building and structuration: the role of leadership. European Journal of Marketing, 40(7/8), 761 - 784. 
Vanharanta, M., \& Easton, G. (2010). Intuitive managerial thinking; the use of mental simulations in the industrial marketing context. Industrial Marketing Management, 39(3), 425-436.

Vargo, S. L., \& Lusch, R. F. (2004). Evolving to a New Dominant Logic for Marketing. Journal of Marketing, 68(1), 1-17.

Von Wallpach, Sylvia, \& Woodside, Arch (2009), Theory and practice of enacted internal branding: Theory, practice, and an experiential learning case study of an Austrian B2B company, in M. Glynn \& A. G. Woodside (Eds.), Business-to-Business Brand Management, Advances in Business Marketing and Purchasing, 15 (pp. 389-425), London: Emerald Publishing.

Wegner, D. M. (2002), The Illusion of Conscious Will, Cambridge, MA: Bradford Books, MIT Press.

Weick, K. E. (1995), Sensemaking in Organizations, Thousand Oaks, CA: Sage.

Wilson, T. D. (2002), Strangers to Ourselves: Discovering the Adaptive Unconscious, Cambridge, MA: Belknap.

Woodside, A. G. (2003), Middle-range theory construction of the dynamics of organizational marketing-buying behavior, Journal of Business \& Industrial Marketing, 18 (4/5), 309335.

Woodside, Arch G. (2006), Advancing systems thinking and building microworlds in business and industrial marketing, Journal of Business \& Industrial Marketing, 21, (1), 24-29.

Woodside, A.G. (2010), Case Study Research: Theory, Methods and Practice. Bingley, UK: Emerald. 
Woodside, A. G., Pattinson, H. H., \& Miller, K. E. (2005), Advancing hermeneutic research for interpreting interfirm new product development, Journal of Business \& Industrial Marketing, 20, 364-379.

Woodside, A. G., \& Samuel, D. M. (1981), Observation of centralized corporate procurement, Industrial Marketing Management, 10, 191-205.

Woodside, A. G., \& Wilson, E. J. (2000), Constructing thick descriptions of marketers' and buyers’ decision processes in business-to-business relationships, Journal of Business \& Industrial Marketing, 15, 354-369.

Zadeh, L. (1965), Fuzzy sets, Information and Control, 8, 338-353. 


$$
\text { Table } 1
$$

Summary of Main Contingent Pricing Decision Paths for Large Order Bids Made by a Distributor in the Office Furniture Industry

\begin{tabular}{|c|c|c|c|}
\hline $\begin{array}{l}\text { Summary of Pricing } \\
\text { Decision Path }\end{array}$ & Path & $\begin{array}{l}\text { Average } \\
\text { Bid (s) }\end{array}$ & $\begin{array}{c}\text { Frequenc } \\
\text { in Percen } \\
(\mathbf{n}=\mathbf{8 0})\end{array}$ \\
\hline 1. Inside track, no renegotiations & $1-2-8-7-10-12-18-19-20$ & $\$ 53,500$ & $35 \%$ \\
\hline $\begin{array}{l}\text { 2. Two distributors representing } \\
\text { same manufacturer product lines } \\
\text { with Steelcase active, plus } \\
\text { additional competitors' bids }\end{array}$ & $\begin{array}{l}1-2-4-6-7-10-12- \\
14-17-19-20\end{array}$ & $\$ 92,000$ & 9 \\
\hline $\begin{array}{l}\text { 3. Inside track (no Steelcase) } \\
\text { renegotiations successful }\end{array}$ & $\begin{array}{l}1-2-8-7-10-12-14 \\
17-18-19-20\end{array}$ & $\$ 80,400$ & 23 \\
\hline $\begin{array}{l}\text { 4. Inside track, } \\
\text { renegotiations unsuccessful }\end{array}$ & $\begin{array}{l}1-2-8-7-10-14-15- \\
18-19-20\end{array}$ & $\$ 117,300$ & 6 \\
\hline $\begin{array}{l}\text { 5. Two distributors representing } \\
\text { same manufacturer's product } \\
\text { lines with Steelcase inactive, } \\
\text { plus other competitors' bids }\end{array}$ & $\begin{array}{l}1-2-4-8-7-10- \\
12-14-17-19-20\end{array}$ & $\$ 83,900$ & 14 \\
\hline
\end{tabular}

Source: adapted from Woodside (2003.) 
Table 2

Fuzzy Set Scores for Customer SOB Awarded to X

Customer Case

Number

5

9

11 $\begin{array}{lcccc}\begin{array}{c}\text { A. Large } \\ \text { Customer }\end{array} & \begin{array}{c}\text { B. Willingness } \\ \text { Single Source }\end{array} & \begin{array}{c}\text { C. Price } \\ \text { Objective }\end{array} & \underline{\text { A.B.C }} & \begin{array}{c}\text { Y. Customer SOB } \\ \text { Annual Agreement }\end{array}\end{array}$

.7

1.0

.8

.3 


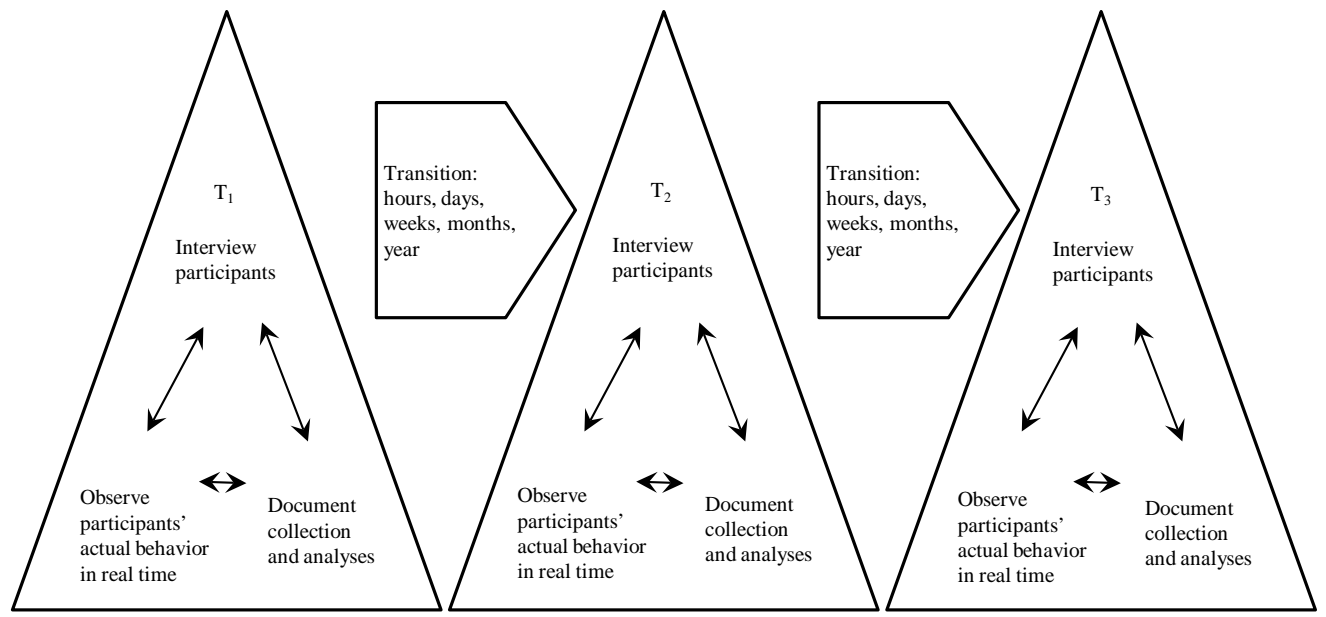

Figure 1. Triangulation in CSR

Note: Showing only three time periods is arbitrary; the key point: the case study researcher often prepares written narratives of his or her interviews, direct observations, and document analyses; then, these narratives are presented to selected participants in the following time period to verify that the narratives include the details reported, observed, and found in the previous time perit 


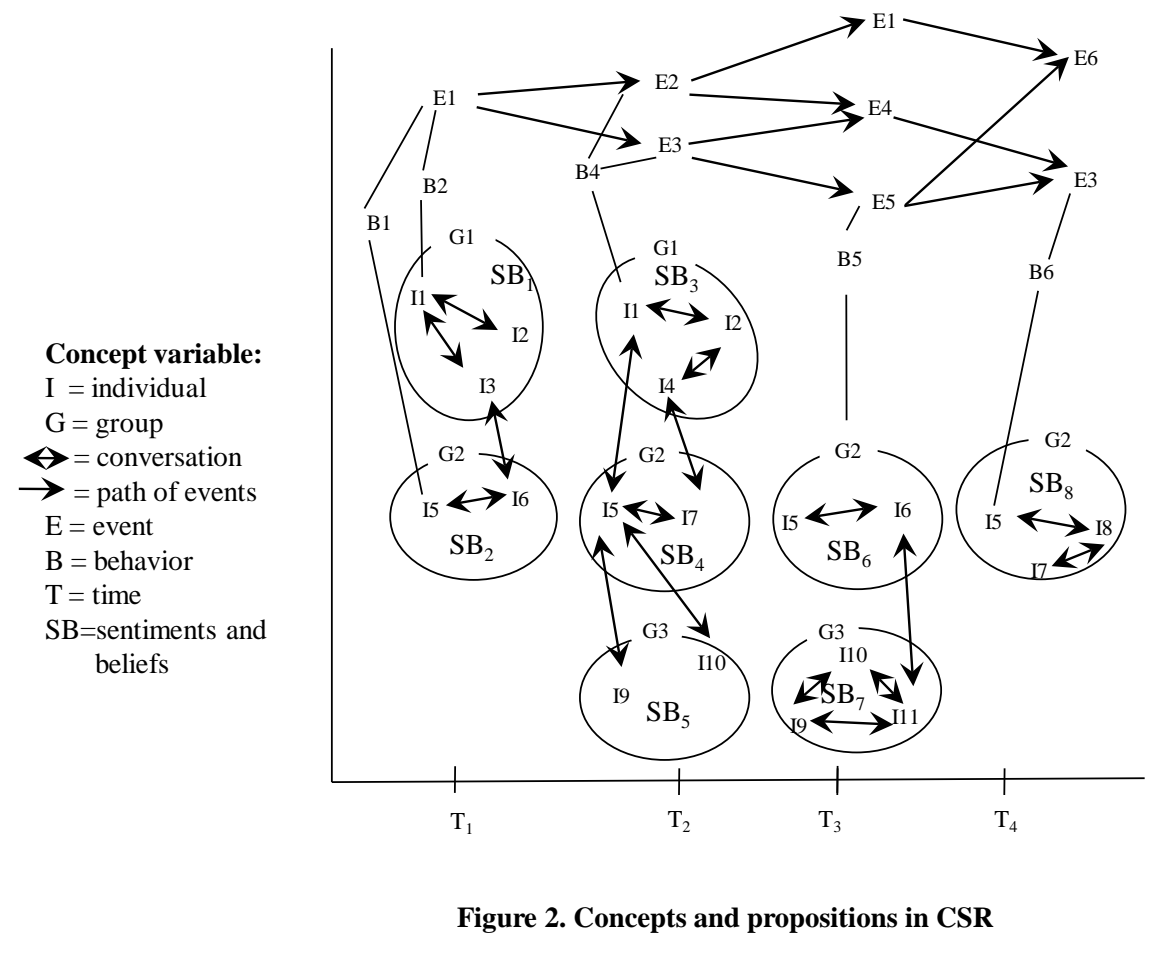

Source: Original figure but relates to Calder (1977, Figure 14.2, p.198). 


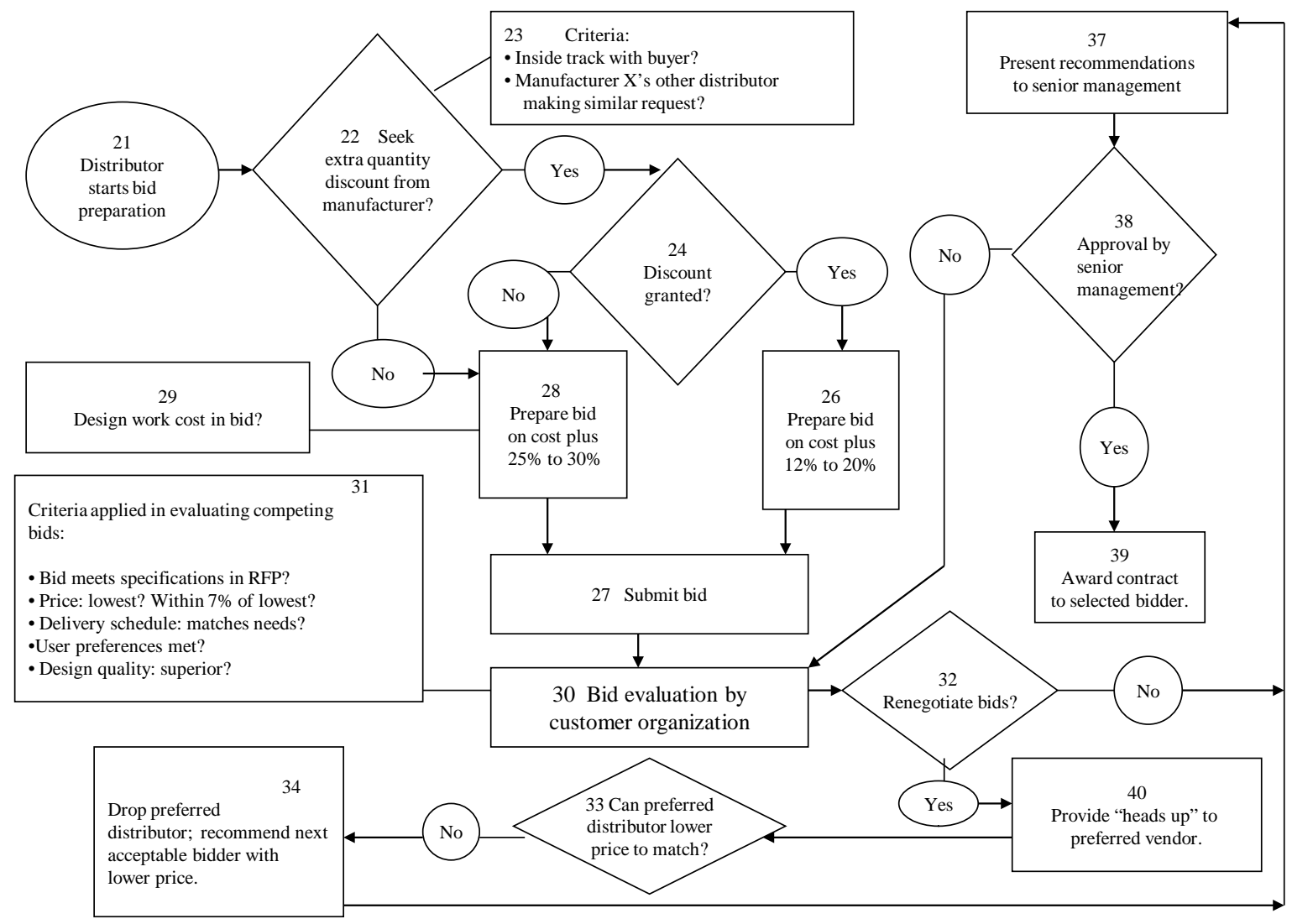

Figure 3. Contingency Model of Large Order Marketer Bid Preparation and Buyer Award Process 


$\begin{array}{cc}\text { Level I } & \text { Emic 1 Interpretation } \\ \text { Participant } & \text { (Mental Model B }(t+1) \\ \text { Sensemaking } & \\ \text { (Subjective } & \downarrow \text { a } \\ \text { personal } & \text { Mental Model A1 to An } \\ \text { introspection } & \text { and Innovation } \\ \text { by informant) } & \text { Decision-Action } \\ & \text { Process (ti) }\end{array}$

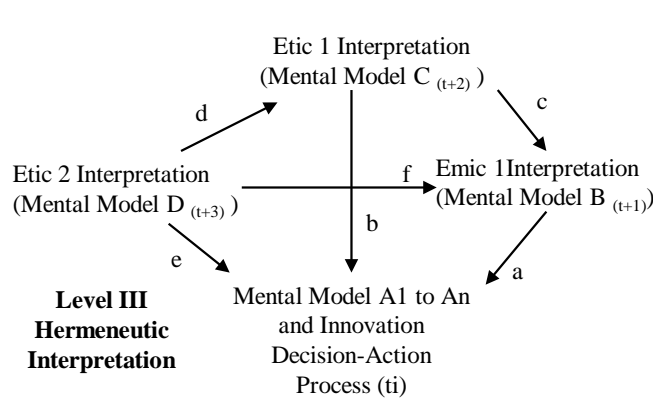

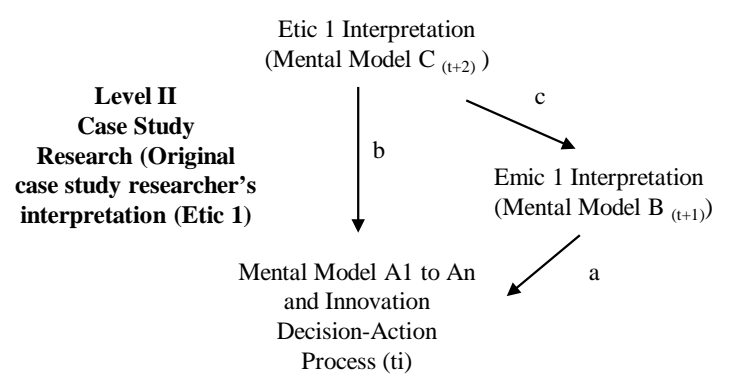

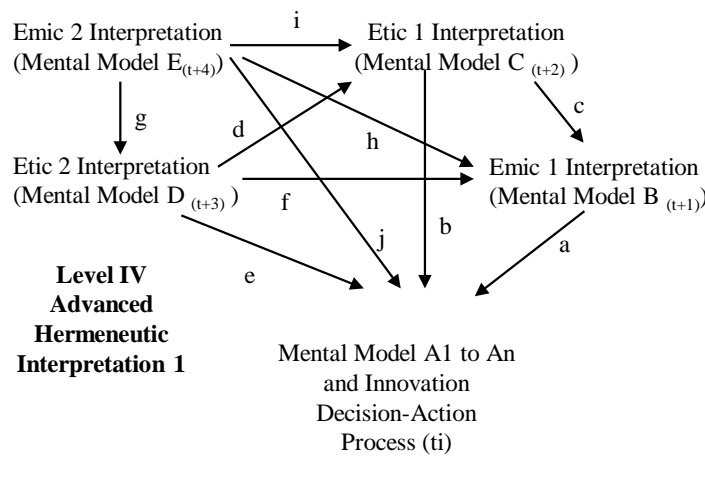

Figure 4

Hermeneutic Interpretation of Sense Making in B2B Innovation Decisions-Action Processes

Source: Adapted from Woodside, Pattinson, \& Miller $(2005,366)$ 


\begin{tabular}{|c|c|c|c|c|c|c|}
\hline \multirow{3}{*}{ Full membership } & \multicolumn{2}{|c|}{$\begin{array}{l}\text { A. Customer has } \\
\text { Large Annual Purchase } \\
\text { Requirements }\end{array}$} & \multicolumn{2}{|c|}{$\begin{array}{l}\text { B. Customer Willingness } \\
\text { To Single Source } \\
\text { Requirements }\end{array}$} & \multicolumn{2}{|c|}{$\begin{array}{l}\text { C. Customer Objective } \\
\text { (Aggressiveness) } \\
\text { with respect to Price }\end{array}$} \\
\hline & +3.0 & 1.0 & $90 \%+$ & 1.0 & "Cost reduction +" & 1.0 \\
\hline & +2.0 & 0.7 & $80 \%$ & 0.7 & “Cost reduction” & 0.7 \\
\hline \multirow[t]{2}{*}{ Cross-over point } & +1.0 & 0.5 & $70 \%$ & 0.5 & "Cost avoidance" & 0.5 \\
\hline & 0.0 & 0.2 & $50 \%$ & 0.2 & "Market price" & 0.2 \\
\hline Full nonmembership $\longrightarrow$ & $\underset{\text { Z-value }}{\uparrow}$ & $\begin{array}{l}0.0 \\
\uparrow \\
\text { Fuzzy Set Value }\end{array}$ & $\begin{array}{c}<50 \% \\
\uparrow \\
\text { SOB }\end{array}$ & $\underset{\text { Fuzzy Set } \mathrm{V}}{\mathbf{1}}$ & "List price" & $\begin{array}{l}0.0 \\
\uparrow \\
\text { Fuzzy Set Value }\end{array}$ \\
\hline
\end{tabular}

Fuzzy Set Scaling Examples

Key. SOBx = share of business awarded to Firm X (our firm)

Code $=$ Buyer statement indicating aggressive stance in price negotiation with firm X (our firm);

- "cost reduction +" indicates buyer want lower price for next year in real terms and extras (e.g., free construction)

- "cost avoidance" indicates buyer wants price increase to be less than rate of inflation 


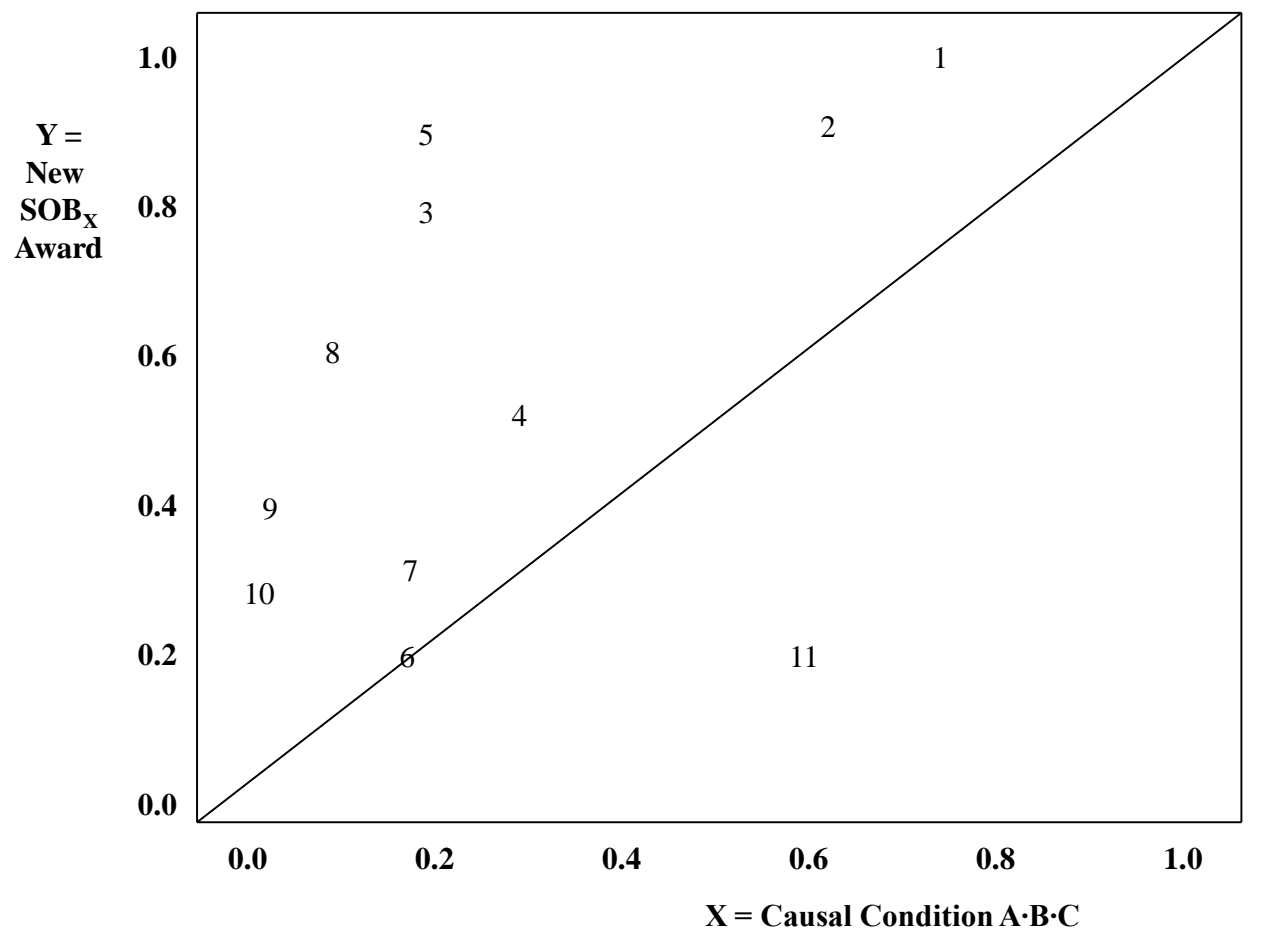

Figure 6

Plot of Y (New SOB ${ }_{x}$ Award) by Causal Condition A·B $\cdot \mathbf{C}(n=$ Customer Case Number $)$

Note. Consistency $\left(\mathrm{Y}_{\mathrm{i}} \leq \mathrm{X}_{\mathrm{i}}\right)=\sum\left[\min \left(\mathrm{X}_{\mathrm{i}}, \mathrm{Y}_{\mathrm{i}}\right)\right] / \sum\left(\mathrm{X}_{\mathrm{i}}\right)=1.00$ without customer case number 11 $=88$ with customer case number 11 Coverage $\left.(\mathrm{Xi} \leq \mathrm{Y})=\sum[\min \mathrm{Xi}, \mathrm{Y}),\right] / \sum(\mathrm{Yi})=.44$ without customer case number 11 $=.45$ with customer case number 11 